\title{
Processes on Uncontrolled Aerodromes and Safety Indicators Part I
}

\author{
Vladimír Plos \\ Department of Air Transport, \\ Faculty of Transportation Sciences, Czech Technical \\ University \\ Horská 3, Praha 2, 128 03, Czech Republic \\ e-mail: plosvlad@fd.cvut.cz
}

\author{
Ladislav Capoušek \\ Department of Air Transport, \\ Faculty of Transportation Sciences, Czech Technical \\ University \\ Horská 3, Praha 2, 128 03, Czech Republic \\ e-mail: capousek@fd.cvut.cz
}

\begin{abstract}
This article describes the processes that take place at the beginning of each duty of dispatcher at uncontrolled aerodromes. Thanks to modeling and analysis of these processes, there is a possible to find critical ones and implement precise targeted safety measures.
\end{abstract}

Keywords - AFIS; Uncontroled Aerodrome; Safety; Safety Indicator; Process modeling

\section{INTRODUCTION}

In the Czech Republic there are a total of 92 aerodromes and 84 of them are uncontrolled. Until this year, at these aerodromes was provided aerodrome flight information service - AFIS. And therefore on each aerodrome were trained persons who can perform AFISO (AFIS Officer).

With effect from this year there is a change in the designation of aerodromes with uncontrolled traffic. Traditional designation aerodrome flight information service may be used only by AFIS stations, which has been certified by CAA and all other uncertified stations are designated as the aerodrome, where the information on a limited scope is provided. Simply, we can say that uncertified stations provide information in the same range as before the change, and certified stations must meet higher demands on equipment and there is a certain professionalization of the staff responsible for providing this service. [1]

Rules and procedures for the providing of AFIS and for providing information on a limited scale are set out by "L" regulations and other legislation. The main activity of authorized person is to provide information to the surrounding traffic about activities at the aerodrome and in its vicinity. Other aircrafts reports position and planed activities to the station before entering ATZ or before starting any operations at the aerodrome. Procedures are shown on the models of communication between the station and the other traffic. Due to the fact that AFISO cannot, with few exceptions, give orders, its role is only to inform. Thus to the overall safety of air traffic around the aerodrome contributes mainly serving accurate and current information. In order to give such information, there must be a perfect situation awareness that is ensured either by an unlimited view of the surrounding area, which can be a problem in some situations. The second source of information about aircraft position can be from its crews, but this source is also not foolproof. By observations the aircraft crew did not report its exact position, and in some cases, they even report significantly different position from the real one.

\section{PROCESS MODELING}

The current trend is to continuously improve safety in all sectors of aviation. Support systems for proper functionality of Safety Management Systems are introduced, there is also a development of safety indicators, etc. Thanks to safety indicators we can accurately detect and focus on the problem area and then take targeted safety measures to prevent the occurrence of potential emergency situation.

If we proceed to improve safety in general aviation, one of the areas with the potential to increase safety is a system to inform pilots about the surrounding traffic on uncontrolled aerodromes. There can be, already mentioned AFIS - at certified workstations, or service which provide information about traffic - at uncertified workstations. In order to be able to detect potential crisis points there is a need to model of commonly used processes of the information service provision. Thanks to the analysis of these critical processes, there is a possibility to get a set of safety indicators which will be monitored during normal operations, after that they will be evaluated and thanks to these values, the appropriate safety recommendations could be made.

In the following chapters we will describe the key processes associated with activities to provide aerodrome information service.

\section{A. Processes before the beginning of service}

The first activity upon arriving at the workplace is writing the necessary data to documentation - "the dispatcher diary". There is written down such information as date, times of sunrise and sunset, radio frequency of the AFIS unit, significant issues in surrounding airspace, etc. 
Another task of dispatcher is to check the movement area before operating the aerodrome. This check is carried out in several aspects. Operating areas are controlled in terms of:

- $\quad$ obstacles on the movement area
- the eligibility of movement areas in terms of weather conditions effect

- technical condition of the movement area

Progress of inspection shows the process model in Figure 1.

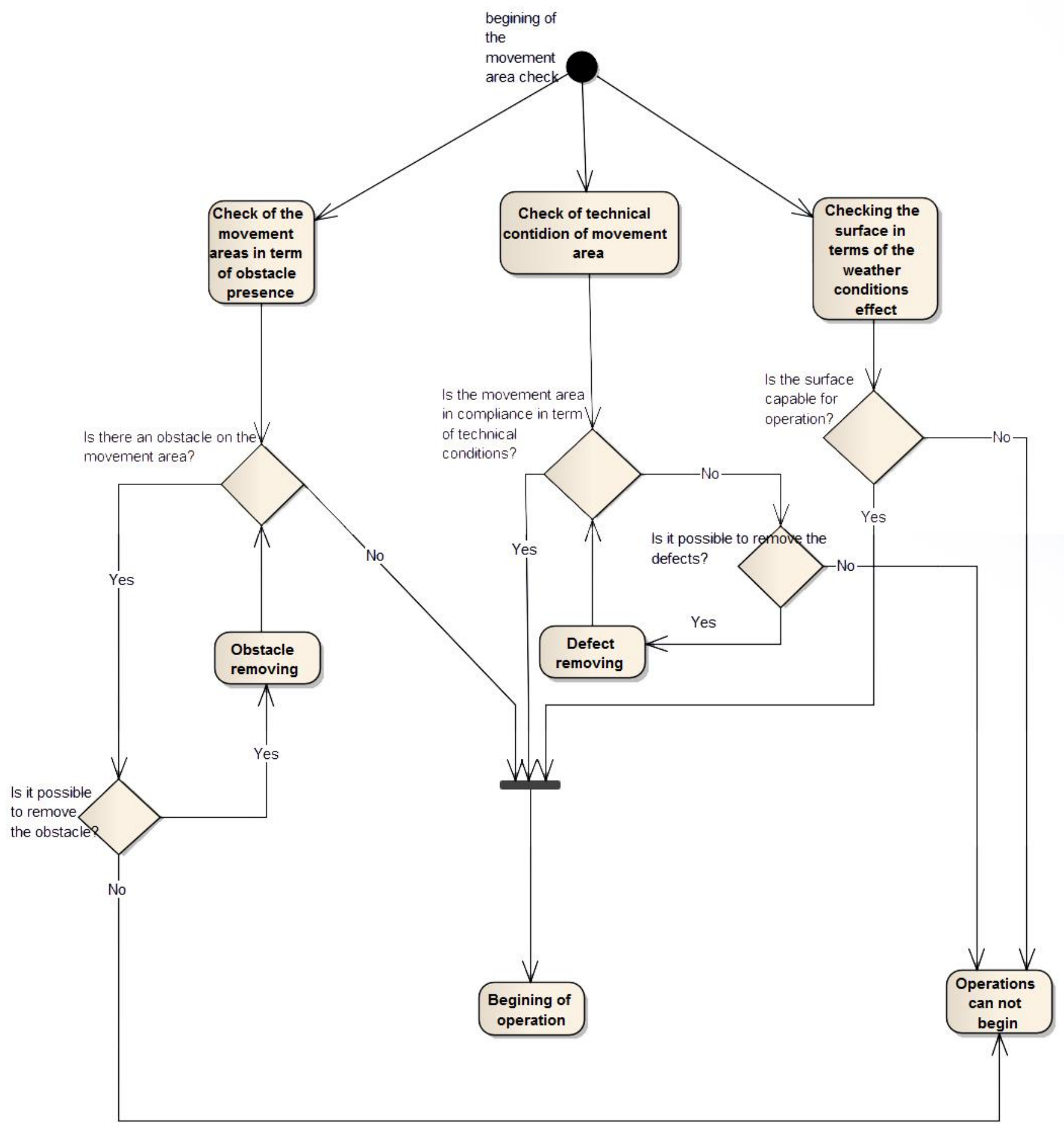

Figure 1. Movement area check (Source: Author) 
Next activity before starting service is to check the dispatcher's workplace. The sources which are necessary for providing information service are checked, such as radios functionality, weather stations functionality and it is also necessary to check if there is a no obstacle in the view at the aerodrome movement area from the workplace. The process of this check is shown in the following figure 2.

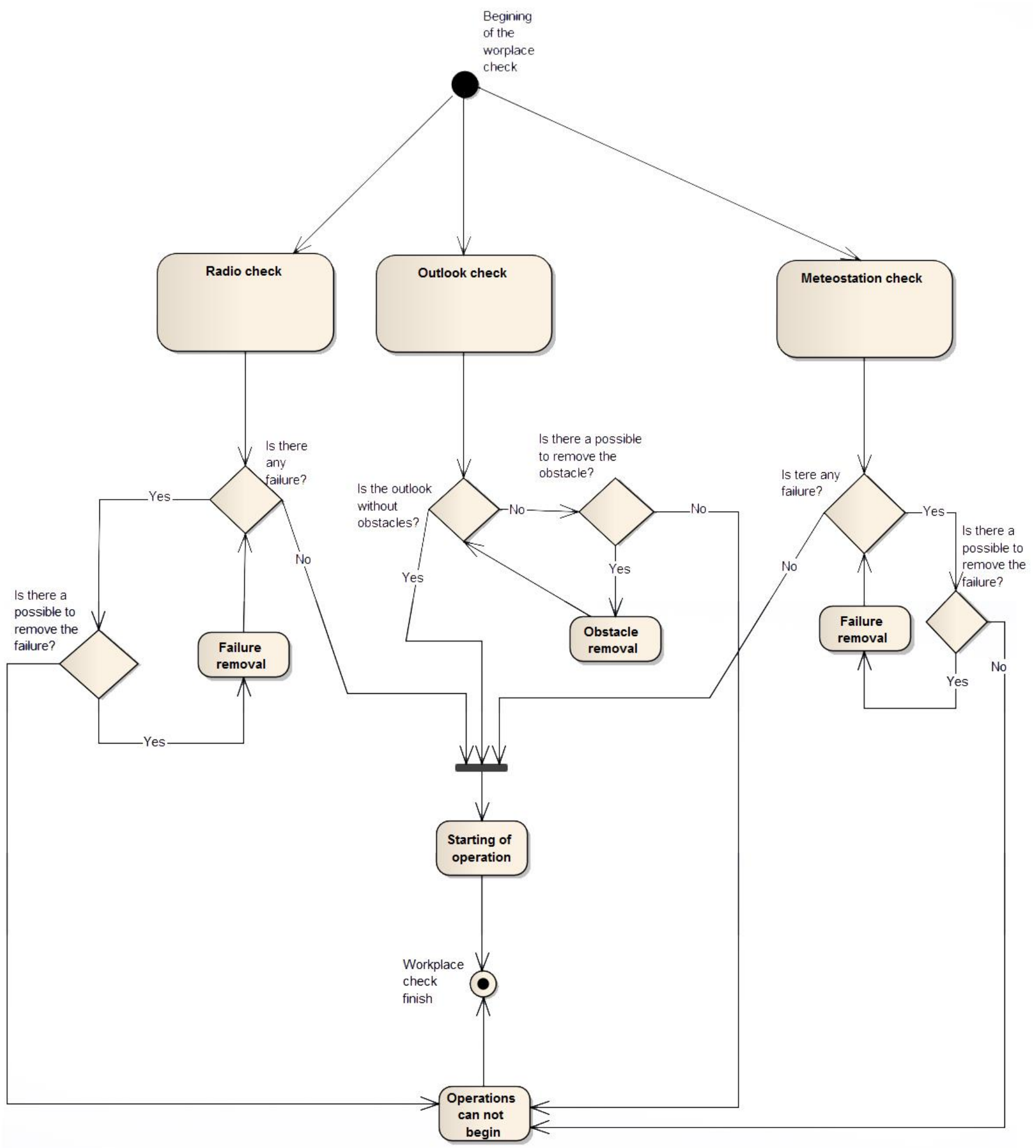

Figure 2. Workplace check (Source: Author) 
After completion of these processes, the tasks associated with the activities of local organizations are following. These activities are to inform the aero club members and other staff at the aerodrome about significant issues on the aerodrome and in surrounding airspace, about runway in use, presence of para operations etc.

\section{B. Processes in communication with the traffic}

Another group of processes are processes in communication with the aircraft at different operating situations. In these, unlike the above-mentioned processes of preparation for service providing, there are already a possibility of non-standard situations with varying degrees of risk. Failure to comply with correct procedures for these processes can result in incidents or accidents. With increasing traffic density increases the risk of losing situational awareness. Therefore, precise cooperation between different actors in the process - the dispatcher and the crew moving around the aerodrome or flying into ATZ is important. The model in Figure 3 illustrates the communication between the participants in the process. It contains several sub-processes of communication, which will be discussed in the next article.

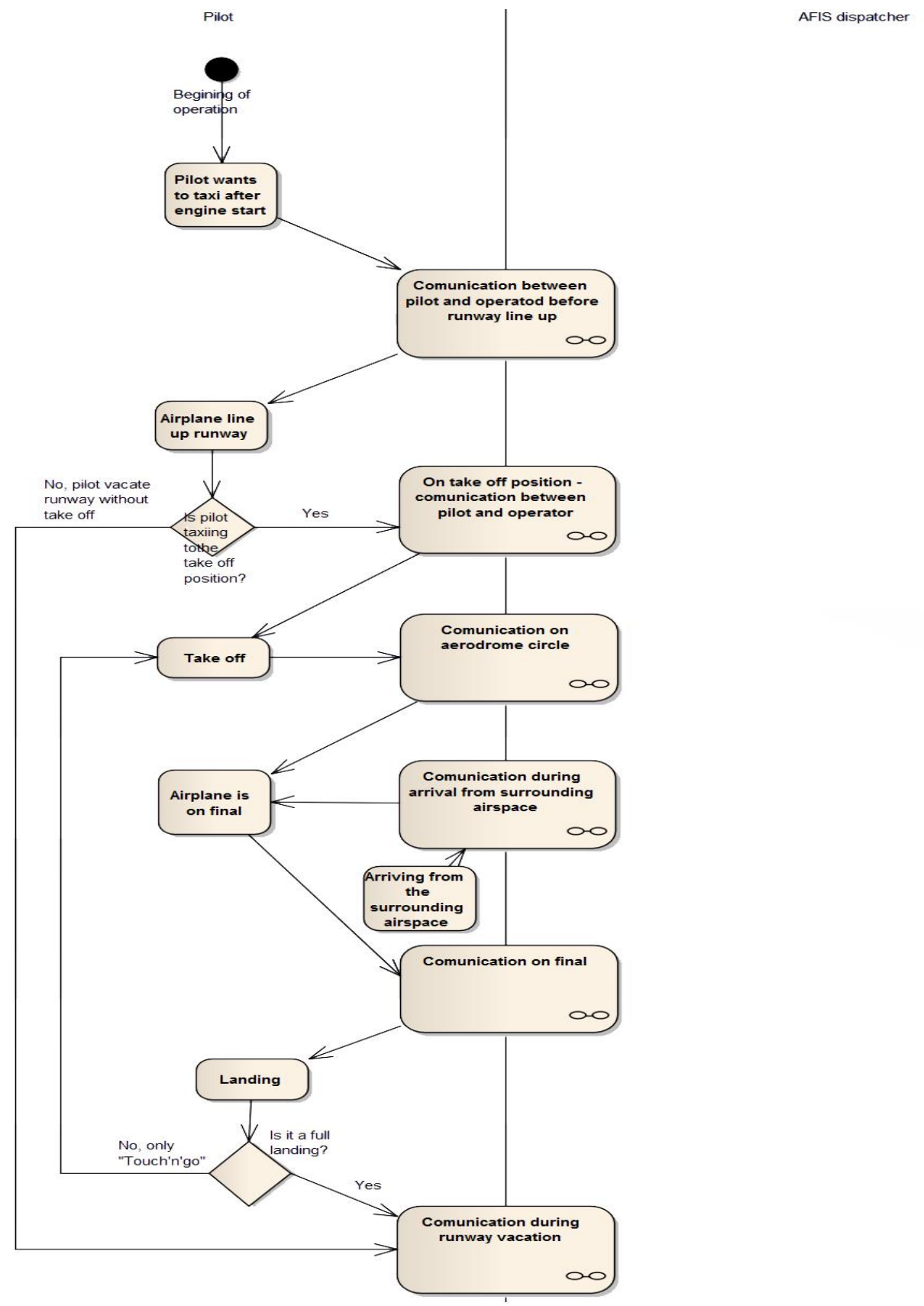

Figure 3. Processes of communication between pilot and dispatcher (Source: Author) 
In the process of communication between the dispatcher and the crew is a high potential that situations affecting the safety of flight will occur. Crosstalk, misunderstanding of information or given incorrect information may result in a dangerous situation.

From the detailed models of processes and hazard analysis there is a possibility to identify areas on which will be good to focus our attention in an effort to improve safety at uncontrolled aerodromes. Thanks to this effort, it is possible to get to the safety indicators, which we set for uncontrolled aerodromes. Thanks to trends, which we will get through evaluating of these indicators, we will be able to take welltargeted safety measures and trace their effectiveness.

From the observations made on the several aerodromes in the Czech Republic, the biggest problem seems to be position reporting of aircraft arriving into ATZ and subsequent fly into the aerodrome circuit. Another problem is situation awareness in dense traffic and from this situation results for example in a giving wrong numbers to land. This leads to a dangerous situation followed by Go-Around procedures and approach repeating.

From the above mentioned issues there is the candidate for the safety indicator in the form of realization Go-Around procedures. Others may be landing on the wrong runway, unannounced entrance on the runway, unannounced fly into ATZ, etc. All such proposed indicators need to be tested in real traffic, whether it is possible to obtain relevant data, which could be evaluated the aerodrome and possibly compared with other aerodromes.

\section{CONCLUSION}

Improving safety on uncontrolled aerodromes in nowadays conditions is not such an easy thing. One way, how to do it is through modeling of procedures, their analysis and introducing of a set of safety indicators which will help us to monitor a level of safety on every aerodrome.

This article discussed the basic processes that are necessary to ensure for the proper functioning and providing of aerodrome information service. Using the above modeling processes that occur on the uncontrolled aerodromes, it is possible to identify critical processes and for these processes determine safety indicators. By monitoring these indicators we can evaluate trends in safety and make targeted safety measures.

\section{ACKNOWLEDGMENT}

This paper was supported by the Grant Agency of the Czech Technical University in Prague, grant number SGS13/090/OHK2/1T/16.

\section{REFERENCES}

[1] Česká republika. Předpis L11: Dodatek S. Praha, 2013. Dostupné z: http://lis.rlp.cz/predpisy/predpisy/dokumenty/L/L11/data/effective/dodS.pdf

[2] ØIEN, K., I.B. UTNE a I.A. HERRERA. Building Safety indicators: Part 1 - Theoretical foundation. Safety Science. 2011, vol. 49, issue 2, p. 148-161. DOI: 10.1016/j.ssci.2010.05.012. available at: http://linkinghub.elsevier.com/retrieve/pii/S0925753510001335.

[3] Eurocontrol AFIS manual. [online]. Eurocontrol. Available at <http://www.skybrary.aero/bookshelf/books/1446.pdf> 